\title{
Zoom al interior: la exploración de la mirada a través de la imagen y el lenguaje audiovisual y sus posibilidades para la intervención con niños y adolescentes desde el arteterapia y el arte
}

\author{
Ana SERRANO NAVARRO ${ }^{1}$ \\ anaserranonavarro@gmail.com \\ Esther CARMONA PASTOR ${ }^{2}$ \\ carmona.esther@gmail.com
}

Recibido: $30 / 03 / 14$

Aceptado: 27/09/14

\section{RESUMEN}

En arteterapia y arte, en el trabajo a través de la fotografía y el lenguaje audiovisual la mirada se posiciona como elemento de construcción identitaria que genera una nueva narración posible de lo propio, en la que la persona autora de su proceso de cambio, puede reconocerse, dándose un lugar y valor diferentes a lo ya contado o ya narrado en su historia de vida; en un marco estructurado que le ofrece la contención y seguridad necesarias para el despliegue emocional desde el que la intervención se articula.

A su vez, estos lenguajes plásticos posibilitan recorridos que caminan de lo individual a lo grupal y de vuelta, haciéndose cargo las personas de sí mismas a través de la obra y el proceso creador, en relación con los otros.

Son lenguajes con los que los niños y adolescentes son, sienten, se muestran, se ofrecen, se comprenden, se redescubren, se miran y son mirados.

Palabras clave: Arteterapia, fotografía, lenguaje audiovisual, niños, adolescentes, mirada, identidad, narrativa, proceso.

\section{Referencia normalizada}

SERRANO NAVARRO A., CARMONA PASTOR E. (2014). "Zoom al interior: la exploración de la mirada a través de la imagen y el lenguaje audiovisual y sus posibilidades para la intervención con niños y adolescentes desde el arteterapia y el arte". En Arteterapia: Papeles de arteterapia y educación artística para la inclusión social Vol.: 9. Páginas 327-347. Madrid.

\section{SUMARIO}

Nuestra mirada: collage de pensamiento. Encuadre teórico-reflexivo. Tres experiencias como estudios de caso. Zoom: conclusiones. Referencias bibliográficas.

\footnotetext{
${ }^{1}$ Arteterapeuta y docente en arteterapia y terapias artísticas. Investigación doctoral en arteterapia y ámbito clínico infanto-juvenil. Hospital de Día infanto-juvenil San Agustín - UCM.

${ }^{2}$ Arteterapeuta en el hospital de día infanto-juvenil HD-CET San Agustín de Leganes.
} 


\title{
Zoom into: exploring looking through image and audiovisual language and its possibilities for intervention with children and adolescents from art therapy and art
}

\begin{abstract}
In art therapy and art, as working through photography and audiovisual language, look is positioned as a building identity element that generates a new possible narration concerning the "self", in which a person, author of his own process of changing, is able to recognize himself, giving himself a different place and value from "the already told" and "already known" about himself along his live story; that takes place in a structured setting which offers him the containment and safety for the emotional deployment which intervention is articulated from.

These are artistic languages as well that make paths able for being walked along, form individual to others, and going back, letting people to take care about themselves through artistic work and creating process.

They are artistic languages where children and teenagers can be, feel, show, offer, understand, find them out, look each other and where people are looked for others.
\end{abstract}

Key words: Art therapy, photography, audiovisual language, children, adolescents, look, identity, narration, process.

\section{CONTENTS}

Our look: collage of thoughts. Theoretical-reflexive setting. Three experiences as case studies. Zoom: conclusions. References.

\section{Nuestra mirada: collage de pensamiento}

Trataremos de compartir en estas páginas aquello que nos ha llevado a proponer experiencias de intervención en relación con la fotografía y el lenguaje audiovisual en contextos clínicos, educativos y sociales, desde nuestro trabajo como arteterapeutas en el primer caso, y desde nuestra mirada como arteterapeutas, en los que restan.

Nuestra posición diferenciada en ellos, como arteterapeutas, como docentes o como mediadoras en cada caso, si bien se ha visto atravesada por la experiencia y mirada clínicas como base desde las que se definen, estructuran y diferencian, nos ha empujado a la necesidad de analizar y deshilar los aspectos y alcances que la intervención a partir de estos lenguajes puede tener en cada uno de dichos contextos.

El texto se desarrolla en un planteamiento explorativo - reflexivo a partir de la práctica, que entendemos como proceso de re-construcción creativa del arteterapeuta en su hacer, a partir de la intervención, del diseño y análisis metodológico, de la supervisión y de la evaluación de dicha intervención, en relación con cada uno de los contextos que describen realidades y de cada una de las personas que dotan de sentido a dichas realidades. 
“¿Es posible - pregunta el construccionista reconstruir el "mundo mental” de una forma tal que ya no sea privado, interior u oculto? ¿Podemos empezar a mirar los pensamientos, los sentimientos, los deseos, los recuerdos, y demás como nacidos de las relaciones y sin sentido fuera de ellas? Si tuviéramos sentido en nuestra reconstrucción, ya no nos veríamos como seres aislados e independientes, fundamentalmente centrados en ir a lo nuestro o en peligrosa competición con los demás. Nos veríamos como una creación relacional. El "yo frete al otro" se convertiría en el "yo a través del otro".

(Gergen, K.J. y Gergen, M.)

Construimos para ello un collage de pensamiento con aquellas sensaciones, intuiciones e ideas que se conformaron como proyectos en la realidad del trabajo con los chicos y chicas. Aquellos hilos reflexivos que supusieron puntos de partida han devenido en conclusiones, que como tales se expondrán más adelante.

Mostramos tres experiencias de trabajo entendidas metodológicamente como estudios de caso, ajustando a ellas los parámetros de intervención específicos desde el arteterapia como disciplina; y revisamos algunos textos, fuentes, teorías, y referentes que trabajan desde una línea de acción-intervención que se asemeja a la que proponemos, a fin de completar nuestra mirada. Son referentes en quiénes nos apoyamos para la revisión, supervisión y evaluación del trabajo, a fin de establecer pautas metodológicas válidas para su implantación en contextos de realidad similares.

Uno de los objetivos que nos planteamos se acerca a proponer algunas pautas eficientes para la intervención en dichos contextos a través del potencial simbólico de las imágenes y sus posibles dimensiones sonoras, espaciales, vivenciales, narrativas, emocionales, sensoriales, terapéuticas, etc.

En el diseño de estos proyectos nunca nos planteamos nada diferente a tratar integrar en nuestra manera de intervenir con las personas, aquello que como artistas nos permitía construir significados propios a partir de imágenes, que vinculadas a nosotras mismas, a nuestras historias y experiencias de vida, posibilitaban un nuevo sentido y con ello un elemento de cambio en nuestro recorrido vital. Como señala Shan McNiff, hay muchos aspectos de la vida que están llamados a ser observados por agentes externos en condiciones especificas, pero la práctica del arte y de la terapia, y de la combinación de ambas en el arteterapia expresiva, demanda nuevas maneras de aproximación desde la investigación, maneras que optimicen nuestro saber y bagaje artístico como valor intrínseco como profesionales.

El marco inicial se estableció en ese juego de impredecible ensayo-error que el arte nos ofrece. En nuestras vidas, cercanas al arte, ensayamos posibilidades desde la imagen que compartimos con los otros. Y quisimos darle un lugar específico desde el hacer arteterapéutico, ahondar en lo distintivo del arte fotográfico y audiovisual, con lo indefinido de los límites que impone y la incertidumbre que 
genera en su proceso de gestación. Y observar lo que empezaba a ocurrir, las respuestas de las personas en su proceso.

"Bajo esta perspectiva es imposible e inconveniente crear un modelo o esquema metodológico cerrado, a modo de recetario, que nos vaya marcando el paso de lo que debemos hacer en cada momento. Más bien debemos plantear algunos criterios que nos hagan avanzar en la creación de "un contexto investigativo más abierto y procesual de modo que los propios resultados de la investigación se reintroduzcan en el mismo proceso para profundizar en la misma."

(Villasante, 1994)

A su vez, el desarrollo se entrelaza epistemológicamente con algunos conceptos fundamentales de la investigación-acción y de la investigación basada en las artes, sin por ello alejarse de una mirada metodológica integradora, que acerque los sistemas, métodos y herramientas para hacerlos específicos de los y las arteterapeutas en la atención y comprensión de las personas con las que trabajamos, apelando a una visión más comprensiva de la investigación, no pretendo negar el valor de los métodos científicos. De hecho creo que las preguntas orientadas cientificamente se revitalizarán si logramos crear un contexto para la investigación más diverso (McNiff, $\mathrm{S}$.).

Desde esta aproximación, una imagen adquiere valor de experiencia en tanto que implica una acción creativa, un ejercicio de acción y de vida. La captura de una porción de realidad que contiene la emoción, el encuentro con el malestar y el deseo, entre muchos otros aspectos, es un acto creativo de libertad y expresión.

Cuando además, ofrece a la persona a posibilidad de poder abordarla como si de un escenario de vida se tratara, con los sonidos, la iluminación, los personajes, el espacio, y el argumento que imagina, que recuerda o que inventa, construye una narrativa de su realidad que desde el presente contempla y completa, dándole un sentido y un significado que lo son tal en relación con esa misma experiencia de creación de la que es fruto.

Dicha experiencia, en el marco en que se desarrolla y tomando como definitorios todos los elementos convergentes, sistematizados en su contexto, aporta material suficiente para la investigación y la generación de conocimiento.

Entre esos elementos, haremos zoom a la mirada del creador/a, desde la que mira, observa y discrimina la realidad; desde la que se mira, la que le permite entender el valor de ser mirado; desde la que contempla su obra y la obra de los otros, esos otros que devuelven al ser una sensación de pertenencia, de vinculación personal más allá de lo biográfico, más allá de lo aprendido. 


\section{Encuadre teórico-reflexivo}

\section{- La imagen multidimensional: de la imagen fija al relato audiovisual}

En ocasiones para el niño/a es más fácil trasformar su pensamiento en imágenes que traducirlo a palabras. De esta forma adquiere una dimensión distinta, más cercana a la realidad.

La cámara da la posibilidad de explorar la realidad, de captarla y transformarla. La imagen a través de su intervención puede adquirir una nueva dimensión que incorpora el tiempo y el sonido. Puede hacer incluso que el pensamiento pueda ser tocado, visto, escuchado,..., logrando que la experiencia estética cambie el pensamiento dotándole de un nuevo sentido.

Las técnicas narrativas hablan de cómo el paciente, el usuario, el alumno, se trasforman en el sujeto que construye la historia y como a partir de este acto de externalización se puede comenzar a analizar cada parte de este proceso.

En la fotografía y el lenguaje audiovisual también existe este acto de externalización pero existe un factor que lo convierte en algo más cercano y fácil, que es el uso del propio lenguaje audiovisual. El trasformar el pensamiento en palabra conlleva un manejo complejo del propio acto lingüístico no propio de ciertas edades o etapas vitales. En cambio si esto es traducido en imágenes puede resultar más sencillo. Coincidimos con los autores que las experiencias emocionales $y$ audiovisuales son decisivas en la construcción de la identidad personal y en las posibilidades que se establecen en la educación para la vida, para la felicidad y para el bienestar (Gutiérrez, Pereira y Valero).

De la dimensión simbólica de esta transformación surge el hecho artístico, la obra. Una sola imagen o una secuencia de ellas que entre sí interactúan y dialogan.

Este diálogo puede establecerse desde lo propiamente visual a través de técnicas más cercanas a la fotografía tradicional o incorporando aspectos y usos propios de la fototerapia: contemplación, proyección, análisis, etc, o dinámicas de transformación a partir de la incorporación de otras técnicas o formatos que provienen de los procesos plásticos y artísticos: manipulación, edición, retoque, integración de otros lenguajes, conversión en nuevas obras y formatos, etc. que se reconstruyen a cada paso: desde la toma, hasta la contemplación, la edición, la separación de la obra, su reutilización, o la construcción de un proyecto artístico propio que se sostiene en el tiempo.

Afirma en sus escritos Judy Weiser que los contenidos visuales de una imagen fotográfica en sí misma son importantes, pero el significado de estos contenidos para cada persona que la rodea también lo son. Una foto significará algo distinto para la persona que la tomó (tanto si posó para ella como si fue "capturada"), para cualquier persona que posteriormente la observe (más allá de su familiaridad con los temas presentes en la foto o en el fotógrafo), y desde luego para cada persona que la guarda como parte de una colección o por ejemplo, de un álbum familiar, sin olvidarnos de la obra que se genera y consolida como parte 
de un proceso personal arteterapéutico, que construye una nueva narrativa para la persona y para la arteterapeuta, en ecuación triangular indivisible con la relación vincular entre ambas. Igualmente la obra que se desarrolla en determinado contextos educativos y sociales si el ajuste metodológico se hace en pro de esa mirada a la autoría como la acción del ser.

A partir de una sola imagen, como ya hemos adelantado, puede a su vez construirse un audiovisual, tan solo incorporando la impronta de una voz, o estableciendo una relación de la propia imagen con el sonido de la persona, de su cuerpo, del espacio y del ambiente.

Varias imágenes se entrelazan configurando un pequeño clip, desde la repetición estructurada o desde la descripción temporal y narrativa de ellas, de lo que ocurre entre ellas y las pone en relación. Y de ahí al video, a la cámara de vídeo que ofrece un registro casi completo y siempre parcial y subjetivo de la realidad, integrando elementos propios del lenguaje cinematográfico, desde la gestación de una idea hasta su desarrollo y proyección.

Sin olvidar, que todos estos elementos, son puestos al servicio de la relación vincular y el marco o encuadre establecido, sea cual fuere el contexto, al son y ritmo del proceso individual de creación acompañado, y del marco grupal de comprensión de la experiencia, como una manera de construirnos en ese relato pues indagar el mundo interno implica tratar con el relato construido sobre sí mismo. No siempre consciente, el relato propio, aflora en cada una de nuestras manifestaciones (Rueda, $\mathrm{O}$ ).

\section{- La mirada: el punto de vista}

En las dimensiones posibles para la imagen, decidimos hacer zoom a algunos elementos clave o conceptos, que son indicadores clave en el proceso. Uno de ellos es la mirada, contemplada en sí misma desde diferentes ángulos:

- Dónde se sitúa el que mira en relación con lo mirado/observado

- Qué parcela de realidad se decide mirar.

- Lo mirado, la imagen que es mirada: desde dónde se mira/se observa.

- Desde qué punto de vista y qué posición se toma ante ella: como creador/a, como observador/a, como algo ajeno, como algo propio.

- Los binomios y polaridades: la ausencia y la presencia, el silencio y ruido, etc.

- La huella, el rastro,... los indicios de la voz, de la historia, que nos hablan no tanto de lo que la imagen describe como de lo que la persona que crea la imagen tiene necesidad de contar.

- Quién más mira/observa lo mirado: la arteterapeuta, las personas, los compañeros,...Persona - grupo $\rightarrow$ Grupo - Persona, a través de la obra.

De esta forma la persona se posiciona y ubica dentro del grupo y el grupo se genera como el encuentro de cada una de esas las personas.

Desde el análisis de la propia mirada, logramos entender el autoconocimiento como un descubrir a través de la propia mirada en relación con la mirada del otro, 
que no solo construye un yo sino también un nosotros. Un nosotros que conjuga la suma de las miradas del grupo, que no es una sola sino que son la multiplicidad de miradas de cada uno confluyendo en un espacio seguro que es común y que favorece la expresión de material emocional, en gran medida inconsciente, para su concreción, elaboración, estructuración, etc....

La interrelación construye una nueva forma de mirarse y entenderse, nos ayuda a comprendernos y tolerarnos, en un ejercicio de reconocimiento en la obra que es mirada, que nos mira y en la que nos miramos. Con respeto y cuidado mutuo pues ver una creación es, de algún modo, ser invitado a la casa ajena. A nuestra mirada extranjera se impone el espacio del otro, yendo es espacio más allá del otro incluso. Podemos deslizarnos, con permiso, preguntándonos más por la disposición de los elementos que por el significado de los mismos. Por qué de los pasillos, por qué de la disposición de un lugar para guardar unos elementos, y no otros, tratando de familiarizarnos con ese modo de disposición que obedece a una vida, en un tiempo, en un lugar, en un existir. (López, M).

En los diferentes contextos de trabajo que presentamos, se repite una constante que mantiene una relación pendular, oscilante, de ida y retorno, con el vínculo que somos capaces de favorecer con los niños, niñas y adolescentes con los que trabajamos.

En ese vaivén pendular relacional, se configura la huella de la mirada que hacia ellos constituimos, una mirada que puede ser reparadora y estructuradora, en muchos casos, y de alcance exponencial cuando no existe aquella mirada que desde la más temprana infancia habría de ser necesaria para el desarrollo emocional y personal del individuo. Ni existe, por tanto, el recuerdo ni la huella emocional ligada a dicha experiencia de cuidado, de ese llegar a ser a través del otro. Barudy y Dantagman contemplan tres aspectos en la espera efectiva del buen trato: la necesidad de vínculos profundos, la necesidad de aceptación y la necesidad de ser importante para el otro.

Esa nueva mirada posible, hace de espejo en el que la persona puede mirarse y verse reflejada, sentirse acogida en su integridad, sin juicio, con la necesaria confianza que emerge de la mano del arte y de sus procesos. Hallarse en la mirada del otro que puede comprender lo que acontece y se asoma a través de esa nueva ventana que el lenguaje simbólico ofrece, en este caso, a través de la imagen fotográfica y el leguaje audiovisual.

Desde ese lugar de acogimiento es posible confrontar aquellos paisajes a donde asomarse no resulta fácil. La confrontación se refiere a una contención que no posea características de represalia, de venganza, pero que tenga su propia fuerza. [...] Que los jóvenes modifiquen la sociedad y enseñen a los adultos a ver el mundo en forma renovada; pero donde existe el desafio de un joven en crecimiento, que haya un adulto para encararlo. Y no es obligatorio que ello resulte agradable (Winnicott, D.). 


\section{- La persona como creadora de su proceso}

El proceso creador, en tanto que otorga protagonismo de acción a quién lo emprende, se asimila al proceso de trasformación y crecimiento que se desarrolla a lo largo de un proceso arteterapéutico, incluyendo en éste "hacerse cargo de uno mismo", tanto en la creación como en el espacio de trabajo arteterapéutico, incluyendo en éstos aquellos aspectos de decrecimiento, retrocesos, dificultades y dudas, a las que se tiene derecho y a las que la persona ha de enfrentarse. En ese sentido, estructurar y reestructurar, avanzar en el proceso de subjetivación, pensar la vida como un proyecto, resolver la infancia y sus identificaciones, salir afuera, generar nuevos espejos en los que mirarse, nuevos ideales, qué queda de lo que pasó, qué permanecerá de lo por venir...Pasado, presente y futuro, la transtemporalidad, convocada para, paradójicamente, dar dimensión y tiempo a la tarea fundamental de generar identidad (Rodríguez, I).

La obra en este proceso se convierte en una extensión de la persona que facilita una mirada "externa" sobre sí misma, que ha de ponerse en comunicación con su yo interno (deseos, miedos, aprendizajes...) en relación con una posible resonancia intra-psíquica, de la mano de un diálogo paciente-obra-arteterapeuta (entendiendo la figura del arteterapeuta como un acompañante activo en el cambio (empatía. Asertividad, escucha activa,...).

La dignidad se entiende en un ejercicio de reconocimiento en la obra que es mirada, que nos mira y en la que nos miramos, en ese ajuste realidad interna externa que ajusta una respuesta más saludable y adaptativa ante los elementos desafiantes que son propios en las etapas de desarrollo infanto-juvenil.

La escena se completa, de nuevo, al encuentro del propio proceso personal con el proceso de los otros que también configuran el espacio de trabajo e intervención. De esta dimensión relacional surgen a menudo las mejores y más ajustadas intervenciones, bien sea desde lo puramente estético, artístico y procesual, como desde la palabra acompasada y que acompaña al proceso. A menudo ocurre en una visualización final de los trabajos, o en la visualización del registro de parte de una sesión, de un cierre o del trabajo de una persona. Sucede que la imagen nos llega, se genera el silencio, se contiene la respiración y la emoción se hace tangible.

Sucede que los demás observan, escuchan, respetan y sienten. Sucede que se encuentran con aquel cuyo trabajo observan. Sucede que a veces logran ponerle palabra, y a menudo no es necesario. A menudo, el método arteterapéutico anima a la expresión creativa en el producto artístico y promueve la comprensión artística del contenido no verbal (Tinnin, L. y Howie, P.).

Con ello sucede también que la palabra, en el trabajo con los niños y adolescentes, adopta un rol perfomántico, más allá de lo meramente lingüístico, sellando de alguna manera el proceso al que nos referimos, que no deja de ser un intento de comunicación y expresión propias, libres. Desde lo sonoro, que le da voz lo completa. 
Volvemos así a la idea del proceso arteterapéutico, y de cualquier otro proceso en el que median las relaciones y las capacidades puestas en juego, como proceso creativo. Nos resulta esclarecedora la mirada al respecto de Carl Rogers, cuando nos dice que

Cualquiera que sea el nombre que le asignemos -tendencia al crecimiento, impulso hacia la autorrealización o tendencia direccional progresiva- , ella constituye el móvil de la vida y representa, en última instancia, el factor del que depende toda pscioterapia. No es sino el impulso que se manifiesta en toda vida orgánica y humana - de expansión, extensión, autonomía, desarrollo, maduración-, la tendencia a expresar y actualizar todas las capacidades del organismo, en la medida en que tal actualización aumenta el valor del organismo o del sí mismo. Esta tendencia puede hallarse encubierta por múltiples defensas psicológicas sólidamente sedimentadas. Puede permanecer oculta bajo elaboradas fachadas que nieguen su existencia; sin embargo, opino que existe en todos los individuos y sólo espera las condiciones adecuadas para liberarse y expresarse.

\section{- Los recorridos audiovisuales: las narrativas}

(Rogers, C.)

Son recorridos geográficos emocionales e identitarios: de la memoria, del pasado, de la proyección de futuro y de la introyección.

Del recorrido del trabajo, es la posibilidad que estos lenguajes ofrecen de poder redescubrir experiencias, emociones y percepciones ya vividas a través del análisis de la propia biografía, "encuadrarlas en el pasado", darles sitio, para ponerlas en relación con el presente, un presente que desde el autoconocimiento, la mejora y el deseo de cambio, les permita la continuidad narrada hacia el futuro. Narrar secuencialmente permite recorrer la diversidad de emociones y argumentos, de espacios y tiempos, con la finalidad de ver en una relativa integridad lo que acontece entre el principio y el fin de un relato visual. No hay un instante sino una continuidad de ellos (Raich, L.).

Será imprescindible, como en cada proceso, la necesaria toma de distancia para aprender a mirarse, para lograr así reconocerse:

No podemos quedar atrapados en la forma a la que habiamos llegado. Esto tiene dos momentos muy particulares: la culminación de cualquier proceso creador contiene una fascinación, el objeto se hizo posible; después tiene que surgir cierta distancia con respecto a ese objeto de fascinación, para que el proceso creador pueda continuar su búsqueda.

(Fiorini, H).

De los posibles recorridos, aquel que implica la exploración a través de los sentidos, es uno de los que mayores sorpresas y potencialidades nos devuelve. Más allá de lo visual, aprender a ser y crear desde el olfato, el tacto, el oído permite un despliegue narrativo sensorial y emocional que sorprende a los chicos 
en su propia escucha. Por presencia o por libertad asociativa, proyectiva y simbólica; su recuerdo, la memoria sensorial.

$\mathrm{Al}$ igual que sucede con muchas personas mayores que sufren Alzheimer $\mathrm{u}$ otras enfermedades degenerativas asociadas, los niños a menudo, no mantienen a priori registro cognitivo de una experiencia de vida, pero sí algo del registro emocional asociado a dicha experiencia que se despierta al encuentro con las imágenes.

Desde ese no lugar también emergen también las narrativas de sentido. Un no lugar en un no tiempo.

Como proceso artístico, el trabajo con fotografía y lenguaje audiovisual se estructura como un recorrido en fases en las que podemos detenernos, profundizando en ellas. A la consolidación de un proceso en fases se asocia la constancia, la permanencia, el compromiso, la estabilidad, la capacidad, la tolerancia, la escucha, la creatividad, la búsqueda de soluciones, ... Para muchos niños y adolescentes, a los que hacemos llegar por múltiples canales mensajes de negación, de no valía, de no capacidad, de inconstancia, de inestabilidad, de rechazo, ..., poder diseñar un traje diferente, más cercano a la imagen que ellos sí tienen de sí mismos, quizás de manera aún no consciente, supone un punto y seguido. Un seguir caminando, a un paso diferente.

\section{- Posibilidades para la intervención con niños y adolescentes desde el artete- rapia y el arte}

El éxito de un taller desde estos parámetros no lo da una gran cantidad de medios sino el saber gestionar de la mejor manera lo que se tiene, atendiendo por encima de todo a las necesidades de cada una de las personas a las que atendemos; esto incluye saber respetar sus ritmos y ser muy flexibles, estando y mostrándonos presentes en la relación terapéutica.

La construcción que se genera es devuelta a la persona como parte de sí misma. El proceso es compartido, es consentido, es generoso y respetuoso. De esa manera, la creación es un lugar de experiencia. Para quien la hace y para quien la sabe mirar. Y es, más allá, presencia real. (López, M).

Diversos autores señalan que vivir una situación personal de desestructuración y abandono produce bloqueos emocionales que atrapan al individuo en un círculo del que le es difícil salir por sí solo. El impacto psicológico de la situación le va limitando en la comunicación hasta producir un desequilibrio emocional. Ocurre algo similar en los contextos de falta de cuidado, de atención, de presencia, una actitud activa que se mantiene en muchos hogares, fruto de una desestructura social más orgánica y profunda de lo que se muestra visible.

En el trabajo con niños y adolescentes el arteterapia y el arte vienen a posibilitar vías para la expresión de tales emociones y conflictos, y en este contexto, con el potencial del grupo como marco.

Las imágenes, el lenguaje fotográfico y audiovisual, y sus dimensiones ya analizadas anteriormente, nos ofrecen vías para la comunicación y expresión emocionales, que arraigan además en la actualización del uso de la imagen como 
construcción identitaria y social de manera explícita: redes sociales, perfiles, identidades, espacios virtuales de encuentro, son parte del entramado social en el que las personas con quiénes trabajamos han crecido.

Esto ha favorecido el uso y manejo de la imagen sin la necesidad de introducir de cero una manera de hacer y contar, así como el fácil acceso a dispositivos que nos hacen llegar en imágenes el imaginario personal y colectivo de los grupos. El fotocollage es un medio especialmente útil para el trabajo con adolescentes porque las imágenes se relacionan con su mundo cultural externo, a la vez que su uso evita la consideración de falta de destreza artística (Hogan, S. y Coulter, A.).

El desarrollo artístico emerge procesualmente en paralelo a las relaciones interpersonales, a las dinámicas de comunicación e intercambio que son contenido para el trabajo y la intervención.

Es por ello que encajamos nuestra mirada y nuestra inquietud con nuestra realidad, diseñando propuestas para los tres contextos de trabajo cuyas experiencias y conclusiones han resultado significativas a nivel profesional y personal: un Hospital de Día concertado con la Comunidad de Madrid, un Instituto de Educación Secundaria Obligatoria y una Delegación de Inmigración.

\section{a) CREAtividad y ComunicACCIÓN - Arteterapia a través del lenguaje audiovisual en un Hospital de Día Infanto-Juvenil}

El proyecto de arteterapia en el Hospital de Día se llevó a cabo en convenio de intervención e investigación entre la propia institución y la asociación Argos Arte en Acción, de septiembre de 2010 a diciembre de 2011. El equipo de arteterapia lo componían Ana Serrano Navarro, arteterapeuta referente del grupo y coordinadora del proyecto, y Esther Carmona Pastor, entonces arteterapeuta en formación. La supervisión del mismo estuvo a cargo de la arteterapeuta Mónica Cury Abril, directora del programa general de Arteterapia desde ARGOS Arte en Acción.

\section{Infraestructura e institución:}

El Hospital de Día-Centro Educativo Terapéutico es un recurso de hospitalización parcial de tipo ambulatorio, que proporciona una atención integral e intensiva necesaria en pacientes con trastornos mentales graves, en las etapas del desarrollo infanto-juveniles. Ofrece contención y continuidad a los tratamientos ambulatorios y previene de la hospitalización a tiempo completo.

El equipo clínico está compuesto por un psiquiatra jefe de adolescentes, una psiquiatra de infantil, dos psicólogas clínicas, una psicopedagoga, una terapeuta ocupacional, un enfermero, un ordenanza, una limpiadora, una arteterapeuta coordinadora y una arteterapeuta en formación.

El abanico de patologías integra trastornos generalizados del desarrollo, trastornos de conducta, trastornos del estado de ánimo, trastornos de la conducta 
alimentaria, trastornos hipercinéticos, y otros (esquizofrenias, trastornos de ansiedad graves, trastornos de personalidad).

\section{Encuadre del taller de arteterapia a través del lenguaje audiovisual}

Edades de 15 a 18 años. Máximo 12 participantes.

Sesiones semanales de 90': encuentro con el grupo, vinculación con el proceso (sesión anterior, semana,...); proceso de creación; cierre.

Intervención grupal con atención individualizada.

El planteamiento del taller se hizo desde el interés por el lenguaje audiovisual en los pacientes, para un desarrollo de la creatividad y favoreciendo la autoexpresión identitaria a través de los medios asociados a este lenguaje: la imagen fija y la imagen en movimiento, y la incorporación del sonido y el tiempo.

En principio, el uso de estos lenguajes con fines terapéuticos se define como videoterapia, pero en nuestro espacio, la creación audiovisual se aborda desde el arteterapia como disciplina específica, a partir de la intención creadora de la persona, que a pone a su servicio los distintos lenguajes y formas artísticas que se integran durante el proceso en una creación audiovisual.

\section{Diseño de objetivos:}

a. En relación a los objetivos del Hospital de Día:

1. Actuar sobre el cuadro clínico del paciente, buscando su estabilidad, mejoría y/o remisión de sintomatología.

2. Actuar sobre circunstancias familiares y sociales promoviendo una actitud contenedora y estabilizadora del entorno inmediato, para favorecer así la reinserción familiar y social.

3. Actuar sobre las secuelas del proceso patológico.

b. Objetivos de partida, demanda de la institución:

1. Desarrollo de la capacidad creativa de los pacientes

2. Fortalecimiento de las capacidades individuales

3. Afianzamiento del autoconcepto y la identidad

c. Objetivos específicos del taller de arteterapia:

1. Ahondar en las posibilidades del lenguaje creativo audiovisual en arteterapia.

2. Entender la mirada como un espacio potencial de desarrollo y estructuración personales desde el que abordar un proceso de intervención arteterapéutica.

3. Ofrecer un espacio para la escucha creativa a partir de la escucha interna, ligada a la relación interpersonal del grupo.

4. Poner en juego las capacidades personales, más allá de la patología, en la búsqueda de un lenguaje y simbología propias. 
El desarrollo de taller se acompasa a la creación del vínculo y alianza terapéuticas, que pasó por una necesidad inicial del desarrollo de propuestas, que se transformó en un devenir creativo en las sesiones en las que no existe una necesidad de finalizar un trabajo, sino de trabajar en un proceso personal creativo, al que incorporamos otros lenguajes en función del proyecto de creación que se esté desarrollando. Más allá de eso, la libertad es entendida como la ausencia de una consigna concreta, trabajando sobre los contenidos personales que traen las personas consigo, junto con lo que tiene lugar en el encuentro, a través de los lenguajes de que disponemos, y a los que cada uno aporta, da o resta un significado personal.

Aparecen en el diálogo y narración del paciente (ahora creador) algunos contenidos intra-psíquicos, tales como:

- Las emociones y los sentimientos.

- El yo interno y externo.

- Los otros y yo con los otros.

- El espacio como escenario de vida.

- El cuerpo.

- La memoria.

- Los otros sentidos.

- $\ldots$

Dichos contenidos se hacen visibles, de forma simbólica (distanciamiento estético), a través de la obra, que en el uso de la fotografía y el lenguaje audiovisual puede alcanzar diversas formas:

- El desarrollo de una idea, el proyecto de creación en fases, la comunicación, ... esbozos, bocetos, dibujos, anotaciones,...

- La narrativa personal como fuente de creatividad: los relatos, las letras musicales, las narrativas personales, las lecturas dramatizadas, el diario de vida, los cuentos, ...

- La fotografía: el retrato, el autorretrato, las composiciones,...

- El reportaje fotográfico, el contacto e interacción con la realidad.

- Intervención creativa en el espacio clínico: stickers, carteles, fotografiar con ausencia de algún sentido (ojos vendados, ...).

- El vídeo: stop-motion, animación con plastilina, anuncios, cortos,...

- Los medios de comunicación y redes visuales conectadas.

- Acciones, repeticiones, posibilidad de cambio, toma de decisiones, la presencia de la sombra y el reflejo. 


\section{b) Desarrollo emocional, autoconocimiento y expresión a través del arte en un IES}

El proyecto se llevó a cabo en un Instituto de Educación Secundaria, por la arteterapeuta Ana Serrano Navarro ${ }^{3}$, también docente de Educación Plástica y Visual durante el curso académico 2011-12, en el centro con un grupo de $4^{\circ}$ ESO.

En el ámbito educativo, nuestra identidad como arteterapeutas permea a la acción docente generando espacios híbridos de intervención que conviene analizar, delimitar y estructurar metodológicamente, de cara a la integración de los y las arteterapeutas como miembros integrantes de los equipos educativos.

La presencia de lo terapéutico en el espacio educativo genera disonancias que demandan de los y las arteterapeutas que podamos y sepamos argumentar y delimitar el alcance de ambos y de las intervenciones que en el ámbito educativo podemos o no podemos desarrollar. En muchos centros es difícil hacer visible el espacio arteterapéutico, no siempre por limitación legal sino a menudo relacionada con la dificultad de nombrar la necesidad de un trabajo personal en los niños y niñas, en sus familias y cuidadores/as, y en el propio colectivo docente.

En el caso que describimos, los talleres se plantearon como espacios de arte y de expresión, ligados al contenido curricular a través de técnicas y procesos creativos ligados a la imagen. Se prioriza con la expresión emocional y la identificación personal a través del proceso de expresión-comunicación. Los aspectos vinculares de la relación interpersonal docente - alumno se potencian como eje estructurador del marco de la intervención.

El aula como lugar de aprendizaje - expresión permite canalizar muchas de las primeras experiencias de fracaso vital y emocional a través de la autoexpresión artística, así como la simbolización de conflictos derivados del desajuste de las expectativas, las capacidades y la construcción identitaria en el marco social.

Esto, entre otros factores, lo convierte en un espacio deseable para la integración del arteterapia tanto a nivel grupal como para el abordaje individual temprano de posibles desajustes emocionales, depresión, duelo por separación o pérdida, fracaso y acoso escolar, desórdenes de conducta, de alimentación, trastornos cinéticos y otros, que empiezan a despuntar en estas etapas. Desde esa perspectiva ahondamos en el arteterapia para la prevención y el desarrollo personal.

Entre los objetivos planteados, ajustados a la persona, se encuetran:

- Favorecer una vía para la comunicación más allá del contenido verbal.

- Acoger las diversas capacidades e inteligencias de las personas.

\footnotetext{
${ }^{3}$ Arteterapeuta y docente en arteterapia y terapias artísticas. Investigación doctoral en arteterapia y ámbito clínico infanto-juvenil. Hospital de Día San Agustín. Universidad Complutense de Madrid. anaserranonavarro@gmail.com
} 
- Generar espacios externos a uno mismo sobre los que poder depositar, proyectar, simbolizar aspectos personales.

- Posibilitar experiencias de intercambio y conocimiento personal e interpersonal - Ofrecer sentido de identidad y pertenencia.

- Integrar el carácter narrativo de las experiencias de vida que apoyan la construcción y estructuración psíquicas e identitarias.

A partir de estos parámetros, a su vez, trabajamos como parte del proyecto la visibilidad a través de la intervención artística en el medio educativo, medio de convivencia del que somos parte y en el que pasamos a tomar parte, generando intercambio, debate y reacción.

$\mathrm{Su}$ estructuración es semi-dirigida, con temas abiertos que puedan despertar conexiones emocionales y vinculares con la obra, con el proceso de creación y el proceso de aprendizaje, y con las personas presentes en las relaciones.

Trabajamos a lo largo de los nueve meses de curso escolar, en sesiones de 55 minutos, 2 veces por semana, con apoyo y seguimiento en el espacio de acción tutorial. Algunas experiencias desarrolladas fueron:

\section{- Los procesos de comunicación/incomunicación}

La necesidad: detectamos en el centro problemas de relación por falta de comunicación: flujos quebrados, interpretaciones rápidas y sin reflexionar, falta de autocontrol, tendencia a la agresividad físico - corporal, dificultad de hacer llegar sus mensajes identitarios entre ellos, a los adultos, a los familiares,...

La clave: trabajo en dos fases, por una lado la toma y edición de imágenes, y por otro la reflexión escrita a partir de ellos y a muestra ante los demás.

Contenidos: el proceso de creación, el vínculo, la generación de ideas propias, a través del cartel, la edición digital y la fotografía.

Abordamos: el propio proceso, el trabajo en equipo, la escucha, la empatía, la identidad, la adolescencia como momento vital.

\section{- Nosotros en nuestro espacio}

La necesidad: detectamos igualmente un sentimiento de no pertenencia, de no sensación de libertad ni encuentro, de dificultad en la observación del proceso de aprendizaje que otros alumnos de edades menores siguen, repeticiones, fracasos prematuros, abandono....

La clave: la observación del espacio para la ubicación y la búsqueda de un lugar, el arte como ejercicio de comunicación.

Contenidos: la necesidad e intención de dejar huella como grupo, de comunicarse con la comunidad de la que son parte, a través de las pegatinas y de la observación de su repercusión en el espacio a través del vídeo.

Abordamos: la libertad, los no caminos, la reivindicación de la diferencia, la mirada. 


\section{- Las emociones: el reconocimiento}

La necesidad: detectamos en el grupo la necesidad de una mayor alfabetización emocional y autonocimiento para la integración de las experiencias de vida.

La clave: estructuración creativa y psíquica.

Contenidos: cómo me siento, cómo me muestro, cómo reacciono, a través de la fotografía y las narrativas visuales.

Abordamos: la exploración de las emociones, la inseguridad y la falta de conexión con los otros.

\section{- Los contenidos personales: nuestra identidad}

La necesidad: detectamos la necesidad de ahondar en un discurso plástico y expresivo propios.

La clave: la vinculación con el proceso y el compromiso con la obra y los materiales.

Contenidos: las emociones, la luz, la sombra, lo bello, lo traslúcido, lo oculto, la huella, la memoria... a través del fotomontaje y la escritura.

Abordamos: el compromiso, la escucha personal y creativa, el proceso de crecimiento, la dignidad del trabajo, la apuesta por la capacidad.

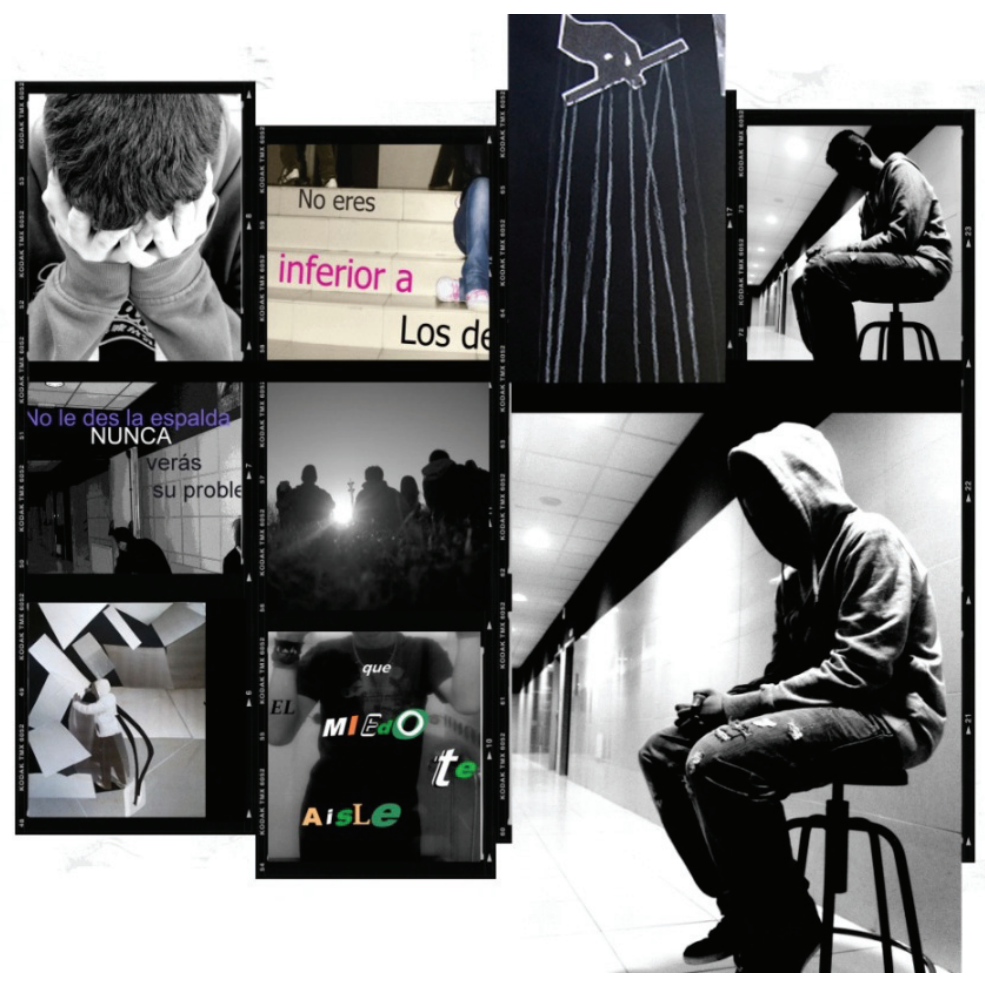




\section{c) Ilustrando mi camino. Delegación de Inmigración San Sebastián de los}

\section{Reyes}

Son una bomba de emociones las que se reciben tras el viaje. Un nuevo país, el reencuentro con los padres, todo lo que se deja, todo lo que se espera... difícil de entender para un niño/a.

La reaprupación familiar es un proceso por el cual los padres migrantes después de un tiempo, generalmente dos años, solicitan el traer a sus hijos. Durante cualquier tipo de proceso migratorio suelen ser los niños/as los que más pierden, los que más sufren ese duelo migratorio, ellos no eligen y ellos no comprenden.

Durante la reagrupación suele producirse una perdida ambigua que como describe Boss (1999) es situación en la que la pérdida es confusa, incompleta o parcial.

El proyecto "Ilustrando mi camino" fue desarrollado durante el año 2010 en San Sebastián de los Reyes Madrid dentro del programa de atención psicosocial a menores y familias reagrupadas lanzado por la Delegación de Inmigración del municipio.

Los objetivos del proyecto se recogen bajo estos dos generales:

- Comprender e interiorizar el proceso migratorio.

- Dar coherencia o adquirir sentido.

- Integrar las emociones y experiencias.

Se desarrolla bajo dos pilares fundamentales como son las narrativas, a través las diferentes técnicas de ilustración, y el trabajo sobre el sentido de coherencia.

Las terapias narrativas potencian el sentido de coherencia. La narración ayuda a dar un nuevo significado a lo que antes era entendido como problema mejorando la adaptación.

Desarrollo del proyecto:

Ilustrando mi camino fue dirigido por la psicóloga del programa, María Pastor y la mediadora intercultural de la Delegación que es arteterapeuta, Esther Carmona.

Se contó con 7 participantes y el trabajo se desarrollo durante de dos semanas.

$\mathrm{Al}$ inicio se realizaba un cuestionario que ayudaban a comenzar cada narrativa.

Este cuestionario analizaba el proceso vivido e intentaba encontrar ese nuevo sentido a la experiencia. Analizaba cada una de las emociones experimentadas.

Tras la reflexión se comenzaba a crear. Eran varias las técnicas con las que se contaba. Cada participante decidió como quería contar y que quería contar de su historia. 


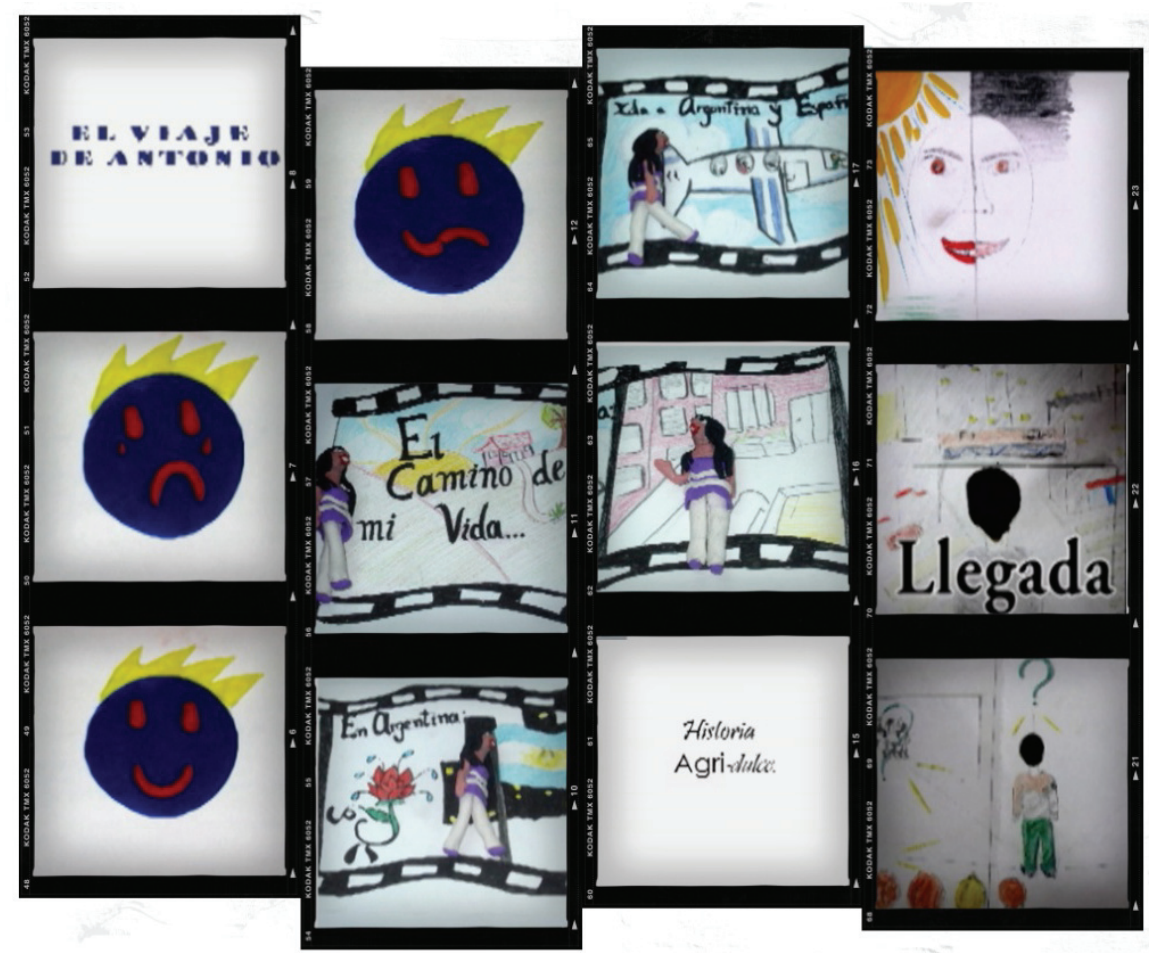

Para poder dar al proceso la dimensión de tiempo al finalizar cada narración se escaneaba o fotografiaba y se montaba con un programa de edición de video al que cada participante añadía música.

Siete viajes, siete historias, siete resultados muy distintos.

El proyecto no quedo aquí, durante los sucesivos meses los participantes tuvieron la oportunidad de ir hablar de su experiencia a tres foros distintos (Clase de magisterio de la UAM, Jornada..., Máster de arteterapia de la UAM) de su trabajo y su vida.

\section{Zoom: conclusiones}

Las experiencias nos muestran cómo aspectos de la vida pueden volver a ser vividos cuando se cuentan. Las palabras/experiencia toman una dimensión distinta cuando van acompañadas de imágenes que soportan contextos, escenarios, personas,... Provocan ser de nuevo vividas y a poder generar nuevas experiencias o pensamientos sobre ellas.

Las narraciones permiten al adolescente trabajar sobre la realidad, no incidiendo en ella, sino sobre la narración que de ella hace, a través de un autodescubrimiento (de sí mismos - potencialidad) en el proceso, en relación con los otros. 
El contexto, los lugares las personas, ... son tan solo una posibilidad, al igual que los medios audiovisuales. Estos se muestras cercanos a las personas que viven y conviven en nuestra sociedad y como unas gafas nos ayudar a ver y ser vistos de la manera más sencilla, enfocando hacia lo que puede ser mostrado.

Este sencillo acto muestra mucho para el que quiere observar el proceso; el arteterapeuta, el educador, el mediador,... que ve lo que se muestra desde lo que no se muestra. De una manera metafórica se pueden mostrar como guías en un museo, el propio de cada paciente, acompañando a observar todo aquello que hasta poderlo entender no se mostro o se dejo ver.

El arteterapia invita a un proceso de vinculación que despoje a los niños y adolescentes de las frecuentes resistencias al adulto como referente. La realidad de la experiencia se construye a través de relaciones. Si el vínculo con la arteterapeuta es fuerte, este abre posibilidades de cambio para la persona, que le lleva a transformación de sí mismo hacia algo más fuerte, consciente, positivo. El poder ver y mostrar un proceso genera un resignificado de toda la experiencia vivida.

Si a algo nos enfrentamos cada sesión es al "yo no sé" frente al manejo técnico de las artes plásticas, cuestión que no se muestras con estos medios ya que son más que cercanos, cotidianos. Se impone la necesidad de desarrollo de habilidades propias que les permitan una mejor y mayor más adaptación a la vida dentro y fuera del espacio clínico, como un tiempo de ensayo para la vida.

El proceso arteterapéutico será significativo para el niño o el adolescente, si le llega de forma que pueda entenderlo, de manera que se aborden sus necesidades de forma integral, apoyándonos para ello en los conocimientos que dan la base a nuestra disciplina y a los que no debemos renunciar. El espacio en arteterapia permite el error y el juego, la incertidumbre, la fantasía, el dolor, la herida y la mejora.

El trabajo a partir de la imagen en sus dimensiones favorece la reestructuración emocional, permitiendo un lenguaje nuevo a través del cual la parte saludable, de vida, de los pacientes, llega de nuevo a ellos y de ahí a los demás.

Más allá del contexto de trabajo (clínico, educativo, social), de la técnica utilizada (cámara de fotos o vídeo, escáner, móvil,...), del uso de la técnica (storyboard, pixelación, corto,...), la imagen muestra un potencial de trabajo incuantificable. La imagen puede ser observada y re-observada y de cada momento en el que es mirada obtener un resultado distinto. Su posibilidad de trabajo es como la imagen infinita que se muestra en sí misma. 


\section{Referencias bibliográficas}

ANTONOVSKY, A. (1987) Unraveling the mystery of health: How People Manage Stress and Stay Well. San Francisco, Jossey Bass Publishers

BARUDY, J. y DANTAGMAN, M. (2005). Los Buenos tratos a la infancia. Parentalidad, apego y resiliencia. Gedisa Editorial.

BOSS, P. (1999) Ambiguous Loss: Learning to Live with Unresolved Grief. Harvard University Press.

FIORINI, H. Formaciones de procesos terciarios. Una tópica del psiquismo creador. Paidós, psicología profunda.

GERGEN, K.J. Y GERGEN, M. Reflexiones sobre la construcción social. Paidós Ibérica.

GUTIÉRREZ MOAR, $\mathrm{M}^{\mathrm{a}}$ C.; PEREIRA DOMÍNGUEZ, $\mathrm{M}^{\mathrm{a}}$ C. y VALERO IGLESIAS, L. F. El cine como instrumento de alfabetización emocional. En Teoría de la Educación. Revista Interuniversitaria, vol. 18, 2006, pp. 229-260.

HOGAN, S. y COULTER, A. (2014). The introductory guide to art therapy. Routledge.

JAES FALICOV, C. (2001/2) Inmigración, pérdida ambigua y rituales. Revista Perspectivas Sistémicas No 69

LÓPEZ, M. (2011). Memoria, ausencia e identidad. El arte como terapia. Eneida.

MCNIFF, S. Artistic Inquiry. Research in expressive arts therapies en Foundations of expressive arts therapy, theoretical and clinical perspectives. Jessica Kingsley Publishers (1999).

MORENO, J.L y ESPADAS, M.A. (2009) "Investigación - acción participativa". En Román Reyes (Dir): Diccionario Crítico de Ciencias Sociales. Terminología Científico-Social, Tomo 1/2/3/4, Ed. Plaza y Valdés, Madrid-México.

RAICH, M. (2014). Poética fotográfica. Casimiro.

RODRÍGUEZ, I. (2009). Grupos de arteterapia con adolescentes. Una experiencia en Hospital de Día en Encuentros con la expresión. Revista de Arteterapia y Artes. Vol. II

ROGERS, C. (1981). El proceso de convertirse en persona. Mi técnica terapéutica. Paidós Contextos.

RUEDA, O. La secuencia de cine como técnica subjetiva en psicoterapia audiovisual en Revista de Arteterapia: Papeles de arteterapia y educación artística para la inclusión social, Vol. 7 (2012). Pág. 189-206.

VVAA. (2013). Using art therapy with diverse population. Crossing cultures and abilities. Jessica Kingsley Publisers. 
WEISER, J. Phototherapy techniques. Exploring the secrets of personal snapshots and family albums. Vancouver, Canada.

WINNICOTT. D. (1971). Realidad y juego. Gedisa editorial.

Web consultadas:

http://extranjeros.empleo.gob.es/es/InformacionInteres/InformacionProcedimient os/Ciudadanosnocomunitarios/Reagrupacionfamiliar.html

http://phototherapy-centre.com/ 